\title{
The face-detection effect: Configuration enhances detection
}

\author{
DEAN G. PURCELL \\ Oakland University, Rochester Hills, Michigan \\ and \\ ALAN L. STEWART \\ Stevens Institute of Technology, Hoboken, New Jersey
}

\begin{abstract}
We have found that a picture of a face is more easily detected than is a pattern of arbitrarily rearranged facial features. An upright face is also more detectable than an inverted face. Using two-alternative forced-choice visual masking paradigms, we have found that this face-detection effect (FDE) can be produced with line drawings and with photocopies of a picture of a face. Our results suggest that a face, as an organized, meaningful pattern, is a more potent stimulus than an arbitrary assemblage of the same visual features. It may be that the FDE is a visual configuration effect. Previous visual configuration effects have been documented only with recognition responses. The FDE, by contrast, documents a configuration effect that affects the detectability of a stimulus.
\end{abstract}

The evidence for visual context effects is growing rapidly. The number of accepted context effects now requires a short list of trigrams just to keep them from becoming confused with each other: There are the word superiority effect (WSE), the object superiority effect (OSE), and the face superiority effect (FSE). Each of these effects has been established using recognition paradigms. For example, in the WSE paradigm (Reicher, 1969; Wheeler, 1970), the observer names a letter located within a string of letters (some of which form words). The observer's choice is restricted to the letters presented in a poststimulus display and, in this sense, the observer makes a forced-choice decision. In the OSE paradigm, the subject must identify one of several target lines. Each target line is embedded within a line drawing that serves as the visual context for the target (Weisstein \& Harris, 1974; Williams \& Weisstein, 1984). Target identification is facilitated when the target is part of a drawing that appears to be a three-dimensional figure or when the target appears to be part of an emergent feature (Enns \& Prinzmetal, 1984; Lanze, Maguire, \& Weisstein, 1985). Using tachistoscopic presentations of real-world scenes, Biederman (1972) showed that objects were harder to identify when each of the objects in the picture was arbitrarily repositioned. The FSE studied by Homa, Haver, and Schwartz (1976) and by van Santen and Jonides

Research sponsored by an Oakland University Faculty Research Grant. The authors thank Chris Kortge, Deborah Delaura, and Louis Bersine for assistance in collecting data. The helpful comments of Keith Stanovich, J. P. H. van Santen, William Schiff, and Thomas Carr are acknowledged gratefully. D. G. Purcell's mailing address is Department of Psychology, Oakland University, Rochester Hills, MI 483094401. A. L. Stewart's mailing address is Management Department, Stevens Institute of Technology, Hoboken, NJ 07030.
(1978) is an example of a still simpler context effect. In the FSE paradigm, a face, either normal or as a set of rearranged features, is presented. Following the face presentation, a single feature (such as a nose) is shown along with variations of the target feature (pictures of other noses, which serve as distractor items). The subject's task is to select the feature that has actually been presented as part of the normal or rearranged facial features. Performance is better when the target feature is presented within the context of a normal face.

It is clear that the visual context can influence an observer's ability to identify an object. This improvement in identification might be the result of enhanced perception of the target item-an enhancement that results from the configuration of the surrounding letters in the case of the WSE and from the arrangement of facial features in the case of the FSE. For the OSE, perception might be facilitated by stimuli that cause themselves to be seen as three-dimensional objects. In other words, the configuration of the stimulus determines its perceptibility. In previous studies of the WSE, FSE, and OSE, subjects reported on a specific portion of the stimulus. This technique provides only an indirect assessment of the perceptual superiority of stimulus configuration. Recently, we developed a direct test of the effects of stimulus configuration on perception, the face-detection effect (Purcell \& Stewart, 1986), which we will refer to as the FDE. The occurrence of the FDE suggests that the detectability of a stimulus is affected not only by its psychophysical properties (luminance, area, etc.), but also by its informational properties (whether the stimulus forms a pattern that is meaningful for the observer).

According to conventional information-processing accounts of perception, identification requires a detailed 
representation, and detection of a stimulus precedes the analysis of a visual scene (Dick \& Dick, 1969; Smythe \& Finkel, 1974). Unlike identification, any perceived change in the visual field is all that is necessary to produce the detection of a stimulus (Dember \& Warm, 1979). Loosely, detection is held to depend on sensory factors, whereas perception is the further analysis of what is detected. Tasks that require discrimination, recognition, or identification necessitate cognitive analysis of what is detected (Sergent, 1983, p. 485). The FDE has lead us to reconsider this account of information processing.

In a series of experiments done in our laboratories, a spatial forced-choice detection task was used to study the perception of faces (Purcell \& Stewart, 1981, 1985, 1986). In other experiments, a temporal forced-choice paradigm was used (Purcell, Stewart, Botwin, \& Kreigh, 1983). With either paradigm, the observers had only to detect the presence of the stimulus. All of our experiments found that the organization of the facial features affected an observer's ability to detect the presence of the stimulus. Our data also show that normally oriented faces are more detectable than either inverted or rearranged faces. The stimuli consisted of line drawings or of black-on-white pictures of faces. The detectability of normally oriented faces, presented under conditions of visual backward masking, was compared with the detectability of an inverted version of the same faces. In other experiments, the detectability of normally oriented faces was compared with a stimulus consisting of rearranged features. Both percent correct location and the detection threshold were used as dependent variables in one experiment or another. For the experiments that used the detection threshold as a dependent variable, the threshold was assessed using the Best PEST algorithm (Lieberman \& Pentland, 1982). In all experiments either a two-alternative spatial or a twoalternative temporal forced-choice task was used. And, in all of these experiments, the configuration affected the detectability of the stimulus.

Our data on face detection thus indicate that even the most basic perceptual task, the detection of the presence of a stimulus, can be influenced by the configurational properties of the stimulus. It is well established that a face is an especially effective stimulus (Gyoba, Arimura, \& Maruyama, 1980; Homa et al., 1976; Spoehr \& Lehmkuhle, 1982, chap. 7; van Santen \& Jonides, 1978). Our data indicate that such effectiveness extends to detection tasks. The FDE provides direct evidence that the configuration of a face can have an effect on its perception. The experiments that follow demonstrate the FDE under a variety of conditions, and serve to outline further its characteristics.

\section{EXPERIMENT 1}

In a study by Gyoba et al. (1980), normal, inverted, and rearranged faces were used as three different stimulus configurations. One of five different types of eyebrows served as the target item. The eyebrows differed from each other only by the angle at which they were set relative to the horizontal axis of the face. The subjects indicated which of the five sets of eyebrows was present on any given experimental trial. As a control, the eyebrows were presented by themselves. Gyoba et al. found that identification was best when the eyebrows were part of a normal face.

An important difference between the experiment of Gyoba et al. (1980) and other studies demonstrating the FSE is the fact that Gyoba et al.'s observers knew in advance which facial feature they were to identify, as well as its appearance. In this respect, the study is similar to the work of Weisstein and Harris (1974), in which subjects decided which of a set of four possible target lines they had just seen.

The following experiment was designed as a basic demonstration of the FDE under conditions in which, just as with Gyoba et al. (1980) and Weisstein and Harris (1974), the subjects knew in advance what the test stimuli were. A picture of a face was presented in its upright, normal orientation, or the face was inverted. A twoalternative spatial forced-choice procedure was used under conditions of visual backward masking. The stimulus was present on each trial, although it was positioned randomly in one of two locations. The subject knew the locations at which the picture would be presented. To detect the stimulus, he or she needed only to pick the side of the target field that was most changed relative to the rest of the visual field. This experiment treated face orientation (upright or inverted) as a within-subjects variable. The position of the target to the left or right of the subject's fixation point was a random variable. Pilot research indicated that the retinal position of the stimulus, to the right or left of the fixation point, had no statistically significant effect on target detection.

\section{Method}

Subjects. The subjects were 15 naive volunteers from introductory psychology classes at Oakland University.

Apparatus. The stimuli were photocopies of a black-on-white line drawing of a face. ${ }^{1}$ Normal and inverted versions of this face were prepared. All stimuli were presented via an Iconix tachistoscope under conditions of binocular viewing. The faces subtended a visual angle of $1.81^{\circ} \times 1.81^{\circ}$. The masking stimulus was a rectangular pattern of overlapping letters ( $\mathrm{N}$ and $\mathrm{O}$ ). The mask subtended $3.2^{\circ}$ in height and $6^{\circ}$ in width, covering the entire central field of view, including the two spatial locations at which the stimuli appeared.

Target duration was fixed at $20 \mathrm{msec}$, and mask duration was fixed at $100 \mathrm{msec}$. The white parts of the target and mask reflected $60 \mathrm{~cd} / \mathrm{m}^{2}$. The continuously illuminated adaptation field was constant at $45 \mathrm{~cd} / \mathrm{m}^{2}$ and contained a small black fixation dot at its center. The face was centered $0.9^{\circ}$ to the left or right of the fixation point, as required by a given trial. All stimuli were presented within a square field subtending $8^{\circ}$ on each side. The experiment was run in a lighted room where the average luminance of the walls was about $30 \mathrm{~cd} / \mathrm{m}^{2}$.

Procedure. A face was presented on each trial. Its position (to the left or right of the fixation point) and its orientation (upright or inverted) were varied in a random order with the constraint that both stimuli appear equally often at both retinal locations.

The subjects were given practice at locating the face. During the practice trials, the interval from the onset of the target stimulus to the onset of the masking stimulus was decreased until a subject correctly detected the face $75 \%$ of the time (averaged across both up- 
right and inverted orientations). This stimulus onset asynchrony (SOA) was then fixed for each subject. Averaged across subjects, this baseline SOA was $53.1 \mathrm{msec}$.

There were 24 practice trials and 48 experimental trials under each of the two conditions of face orientation, giving each subject a total of 48 practice trials and 96 experimental trials. The subjects were told that they might see only bits and pieces of the target stimulus or have only a vague impression of the face, upright or inverted. Regardless of what they thought they saw, they were to make a response indicating whether the stimulus appeared to the left or right of their point of fixation.

The subjects initiated each trial on hearing a signal. They gave their forced-choice responses verbally. A response was obtained after each trial. The subjects were told that their best performance would be obtained if they looked carefully at the fixation point before they initiated a trial. The intertrial interval was about $10 \mathrm{sec}$. Data collection took about $\mathbf{3 0} \mathrm{min}$ for each subject.

\section{Results and Discussion}

Subjects correctly detected the normally oriented face on $76.25 \%$ of the trials. They could detect the inverted face on only $69.10 \%$ of the trials. A repeated measures analysis of variance (ANOVA) on the arc sine transformed percent correct data showed that the difference of $7.15 \%$ was statistically significant $[F(1,14)=4.85, p<.05]$.

The FSE is known to occur when properly oriented faces are compared with either inverted or rearranged faces, and, in this respect, our finding is consistent with the literature on facial stimuli. But our result extends the known superiority of facial stimuli to include detectability. The subjects were required only to make a detection response, although it was not uncommon for them to remark that, on occasion, they had seen the normal face, and that it appeared to be superimposed on the masking pattern. They seldom reported seeing an inverted face. These casual observations suggest that normal faces are not only detected at a higher rate than are inverted faces, but that normal faces can be identified at SOA values at which inverted faces can only be detected. We further investigated this observation in Experiment 5.

\section{EXPERIMENT 2}

A second experiment was designed to substantiate the findings of Experiment 1, and to determine if the detectability of faces would vary as the interval between the onset of the face and the onset of the mask changed. The experiment was designed so that we could determine if, as the SOA increased, the subjects' performance improved at the same rate for normal as for inverted faces. Experiment 2 also used experienced observers as subjects. We reasoned that trained observers would be more confident, and hence would maintain a more stable response criterion, even when the target provided only the absolute minimum of visual information.

\section{Method}

Subjects. Four subjects were run (D.G.P. and 3 undergraduates working the cognitive psychology laboratory at Oakland Univer- sity). Three had had extensive experience as subjects in unrelated experiments on visual backward masking. The undergraduates were not aware of the hypothesis being tested.

Apparatus. The apparatus was the same as that used in Experiment 1 , with the following exceptions. The stimuli consisted of a black-on-white photograph of a woman's face instead of a line drawing. ${ }^{2}$ A picture was used to determine if the results of Experiment 1 could be obtained with a related, but more detailed, stimulus pattern. The picture subtended $1.58^{\circ}$ of visual angle in width and $1.98^{\circ}$ in height.

Procedure. The instructions and procedures were the same as in Experiment 1, with the following exceptions. The baseline SOA was picked so as to yield $65 \%$ correct detection averaged across both face orientations. This value was lower than that of Experiment 1 because four experimental SOA values were used: the criterion SOA and values 5,10 , and $15 \mathrm{msec}$ greater than the criterion SOA. The average SOA values were $27.5,32.5,37.5$, and $42.5 \mathrm{msec}$. Each subject received 80 training trials, 40 upright and 40 inverted faces randomly intermixed. The experimenter determined the baseline criterion SOA during the training trials. During the course of training and the experiment, each subject was reminded frequently that he or she was to respond to the side of the visual field that appeared to be most visually unlike the rest of the field.

There were 48 experimental trials per type of face, collected under four individually determined SOA values, for a total of 384 trials for each subject. The type of face (upright or inverted) was presented in a random order, as were the SOA values. The stimulus was presented to the right or left of the fixation point randomly. The independent variables of type of face (upright or inverted) and SOA were completely crossed in a within-subjects statistical design.

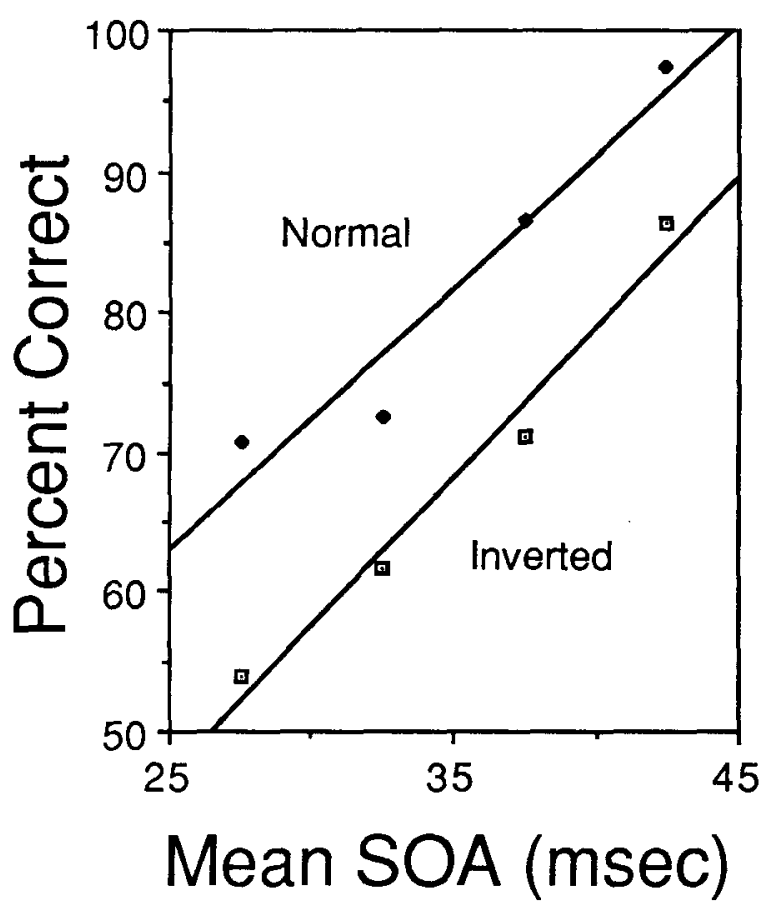

Figure 1. Percent correct localization of the upright picture of a face (normal) or the inverted picture of a face (inverted) in Experiment 2. (Four delays between the onset of the target stimulus and the onset of the masking stimulus are plotted.) 


\section{Results and Discussion}

Figure 1 gives the percent correct detection for upright and inverted faces. The arc sine transformed percent correct data were analyzed using a repeated measures ANOVA. Performance improved as the SOA increased, consistent with the literature on Type B masking functions (Kahneman, 1968). The effect was statistically significant $[F(3,9)=17.87, p<.001]$. More important, the effect of the type of face (upright or inverted) was also statistically significant $[F(1,3)=24.32, p<.025]$. Face type did not interact with SOA $[F(1,3)=0.44]$.

Figure 1 shows that the slopes of the two masking curves are virtually the same. The findings are consistent with the proposition that an upright face is better detected than an inverted face across all SOA values. Whatever perceptual disadvantage results from inverting a picture of a face, the disadvantage, relative to an upright face, is constant at each SOA.

Just as in Experiment 1, subjects reported seeing the normal face occasionally but did not report seeing the inverted face. However, these subjects reported that most of the time they were just responding to the side of the stimulus field that appeared most different during the trial. Thus, performance was based on detection, with identification, if it took place, being incidental to the experimental task.

\section{EXPERIMENT 3}

In Experiment 2, we were careful to ensure that our subjects understood the experimental protocols and knew they were to use any available visual cue to determine the location of the target. The casual comments of subjects in Experiments 1 and 2 had indicated that they may have seen some of the normal face presentations. On occasion they reported seeing phenomenally distinct pictures of upright faces. Such comments were more rare for the inverted face presentations. Because upright faces sometimes appeared to be phenomenally distinct, however, subjects might have developed one criterion for reporting the presence of an upright face and another for an inverted face-criteria based, in part, on the perceived distinctiveness of the stimulus. In extreme cases, it is conceivable that a subject might egregiously ignore the experimenter's instructions and simply respond at random whenever the stimulus fails to appear phenomenally clear and distinct. The phenomenally distinct upright face would then be more likely to be reported than the inverted face. We designed Experiment 3 to eliminate the opportunity for a subject to ignore the experimenter's instruction and to concurrently use one criterion for reporting upright faces and a different criterion for reporting inverted faces.

The normal faces may have become phenomenally distinct on occasional trials due to the method by which we assessed the SOA values used in Experiments 1 and 2 . We averaged performance using both normal and inverted faces as stimuli. Experiments 1 and 2 demonstrate, however, that the upright face is a more effective stimulus in the sense that it can be detected at a shorter SOA than can an inverted face. At any given SOA, then, the normal face should also be closer to its identification threshold than should the inverted face. And, indeed, Experiment 5 shows that the difference between the detection and identification thresholds is smaller for normal faces than for rearranged faces. This presents the possibility that, while converging on the detection threshold, subjects would experience more trials when they can see the normal face than when they can see the inverted faces. Such a difference in the phenomenal consequences for normal and for inverted faces might reinforce a set to look for normal faces only.

Three aspects of Experiment 3 were designed to minimize the chances of an observer's developing a set to look for a normal face at the expense of ignoring equally strong visual cues associated with a nonnormal face. (1) The primary means was to use a between-groups experimental design. One group of subjects was presented only with a normal, upright face. The second group was presented only with an inverted face. Since each subject was presented with only one face type, he or she would develop a set to look for exactly the type of stimulus that was being presented during each trial. If the FDE were due to a bias to look for an upright face and to ignore an inverted face, the effect should not be found in Experiment 3. Johnston and McClelland (1973) guarded against just such a set to respond to words when, in their experiment on the WSE, they ran blocked presentations of words and letters. (2) In addition, subjects were told, after each response, whether or not they had correctly located the face. This feedback was intended to reinforce our instructions to the subjects to choose the side of the fixation field that appeared most different. With feedback, our subjects rapidly learned to detect any perturbations in the visual field that were associated with the target's presence. (3) By using detection threshold as the dependent variable, subjects should, at threshold, be equally unaware of the stimulus, whether it be an upright or an inverted face. This belief is based on work that shows that target localization under backward masking happens at shorter SOA values than does target identification (Breitmeyer, 1984, p. 133; Dick \& Dick, 1969; Smythe \& Finkel, 1974).

\section{Method}

Subjects. Sixty volunteers from the introductory psychology classes at Oakland University served as subjects. They were assigned randomly to a type of face. Thirty subjects were run with an upright face as the stimulus; 30 were run, in the second condition, with an inverted face as the stimulus.

Apparatus. Just as in Experiments 1 and 2, all stimuli were presented via an Iconix four-channel tachistoscope. However, stimulus presentations were under the control of an Apple II+ computer. The computer was interfaced with the tachistoscope by a Cognitive Testing Station card supplied by Digitry Inc. Because of slight equipment differences between this experiment and the previous experiments, the fixation field did not remain on throughout the stimulus trials. The fixation field went off with the onset of the target and returned with the offset of the mask. 
The duration of the target field was set at $15 \mathrm{msec}$ and the mask duration was set at $100 \mathrm{msec}$. The detection threshold was defined as the SOA that gave $75 \%$ detection. The luminance of all stimulus fields was constant at about $48 \mathrm{~cd} / \mathrm{m}^{2}$, except for the target field. The target field was attenuated by a $0.2 \log$ unit neutral-density filter, so that its luminance was approximately $30 \mathrm{~cd} / \mathrm{m}^{2}$. Because of its size, the filter reduced the target field to a visual angle of $4.4^{\circ}$ on each side. Pilot studies showed that the luminance of the target had to be reduced, relative to that of the mask, in order to push the target below the subject's threshold for seeing. The experiment was carried out in a lighted room. The luminance of the room's black walls was approximately $1.17 \mathrm{~cd} / \mathrm{m}^{2}$. The faces and all other conditions were the same as those of Experiment 2.

Procedure. Detection thresholds of SOA were determined with the Best PEST algorithm of Lieberman and Pentland (1982). The minimum step size was $1 \mathrm{msec}$. The subjects indicated to which side of their fixation point the target appeared by pressing one of two response buttons (one on the right side and one on the left). As in the previous experiments, the subjects were instructed to make a response on each trial, guessing if necessary. The face was positioned to the right or left of the fixation point at random. The subjects started each trial upon hearing a ready signal. The experimenter monitored the experiment, changed the stimulus cards, and keyed the onset of the ready signal.

Before the practice session, the subject was shown his or her target stimulus card outside of the tachistoscope. This card had either an upright or an inverted face, depending on which stimulus the subject would be presented with during the experimental trials. This was done so that there would be no ambiguity on the part of the subject as to the type of facial stimulus he or she was to be run with. Each subject was then given practice at spatially locating the face with an SOA of $125 \mathrm{msec}$, so that they were also familiar with the experimental procedure. During the practice trials, it was emphasized that they were to make a response on each trial. Forty experimental trials were then run. Each session took about $15 \mathrm{~min}$, with 10 of those minutes devoted to establishing the detection threshold.

\section{Results and Discussion}

SOA threshold was shorter for upright faces than for inverted faces (upright $=38.77 \mathrm{msec}$ and inverted $=$ $46.27 \mathrm{msec}$ ). This 7.5 -msec difference was statistically significant using a randomized blocks ANOVA $[F(1,58)$ $=4.82, p<.03]$. The results do not support the hypothesis that the FDE is due to the subjects' adopting a set for normal faces. If the FDE results from a situation-specific set that gives an advantage to the normal face, the FDE should not have been found in Experiment 3. The results of Experiment 3 do not rule out the possibility that a set for perceiving a normal face is responsible for the FDE. However, Experiment 3 indicates that such a set must be regarded as a more or less permanent characteristic of the subject's normal processing of visual information, and not something easily changed by short-term situationspecific conditions.

\section{EXPERIMENT 4}

The independent variable in this within-subjects design was face type (normal, inverted, or rearranged). Each of us sees normally oriented faces every day. We sometimes see upside-down faces, for example, in inverted magazines or folded newspapers held by someone sitting across from us. But outside of psychology textbooks, most people seldom, if ever, see an assemblage of rearranged facial features. Upright faces are a salient part of what each of us encounters every day, while inverted faces are much less salient in everyday life, and rearranged facial features have little salience. Therefore, detection should be best with upright faces, less good with inverted faces, and worst with rearranged facial features. If the FDE is related to the perceptual salience of the facial stimuli, the detection threshold should be longer for a rearranged facial stimulus than for an inverted face. The principal goal of this experiment was to determine whether upright and inverted faces were more detectable than an assemblage of rearranged (scrambled) faces.

\section{Method}

Subjects. Twenty-four volunteers from the introductory psychology classes at Oakland University served as subjects.

Apparatus. The apparatus was much the same as in Experiment 3. The target stimulus was a black-on-white picture of a face taken from a newspaper photograph and reproduced on an SCM copy machine. The face had not been used in any of the previous experiments. A new facial stimulus was introduced to make sure that the FDE was not restricted to a particular set of facial features. Pilot data had shown that, with this face, the luminance of the target field did not have to be reduced to produce effective masking.

Three versions of the stimulus face were created. One was the normal, upright face. The second was the same face rotated $180^{\circ}$ so that it was inverted. The third version of the face was composed of rearranged facial features: The eyes, the nose, and the right and left halves of the mouth were punched out of the face, and a different feature was repositioned within each hole. The features were arranged, top to bottom and left to right, as the nose, the right side of the mouth, the left eye, the right eye, and the left side of the mouth. Although the features had been repositioned they maintained their normal orientation, as did the head itself. The picture of the face subtended a visual angle of $1^{\circ}$ in height and $1.25^{\circ}$ in width. The face stimuli were centered on points $1.12^{\circ}$ to the right or left of the central black fixation dot. Faces were presented either to the right or left position as required on a given trial.

The hair and neck were trimmed from the pictures to restrict the facial features to the eyes, nose, and mouth. The hair on this face was visible as a dark blob, unlike the face used in Experiments 1 and 2. We felt that it was important that care be taken in constructing the new stimuli to eliminate this additional feature so that the large dark area formed by the hair would not provide a prominent feature that would be detectable in its own right.

Procedure. The procedures were like those of Experiment $3 \mathrm{ex}$ cept that each subject was presented with three facial stimuli (upright, inverted, and rearranged), in a random order. The orders of face type and their position were counterbalanced randomly. No feedback was given. Each subject received two practice trials at an SOA of $100 \mathrm{msec}$ with each of the three facial stimuli, one to the left and one to the right of the fixation point. The threshold for each type of face was then determined over the course of 40 trials for each face type, for a total of 120 experimental trials per subject. A complete session took about 25 min.

\section{Results and Discussion}

The mean threshold detection SOA values indicate that normal faces are detected at shorter SOA values than are inverted faces, and that inverted faces are detected at shorter SOA values than are rearranged faces (upright $=$ 
$34.75 \mathrm{msec}$, inverted $=47.50 \mathrm{msec}$, and rearranged $=$ $53.79 \mathrm{msec}$ ). A one-way repeated measures ANOVA indicated a statistically significant main effect $[F(2,46)=$ $26.68, p<.001$ ], indicating that the more familiar a subject is with a stimulus pattern, the more likely the stimulus is to produce a detection effect. And, in a planned comparison, it is clear that the detection threshold of the inverted face is significantly different from the longer detection thresholds obtained with the rearranged facial stimulus $[F(1,46)=5.61, p<.025]$.

This experiment sheds further light on the reason for the phenomenal emergence of upright faces at SOA durations too short to allow the inverted faces to be seen. Averaging the thresholds of the normal and inverted presentations produces a value that is analogous to the pretest criterion threshold settings made in Experiments 1 and 2 . This pretest criterion stimulus setting would provide an SOA that was about $6 \mathrm{msec}$ above the detection threshold for a normal face. This same SOA would be about $6 \mathrm{msec}$ below the detection threshold for an inverted face. In Experiment 5, we will show that the identification or classification threshold for normal faces is approximately $10 \mathrm{msec}$ greater than the detection threshold. Thus, the threshold averaging process used in Experiments 1 and 2 would have resulted in a normal face's being run at an SOA that was approximately $4 \mathrm{msec}$ from its identification threshold. This might be the reason why subjects in Experiments 1 and 2 reported seeing normal faces from time to time.

\section{EXPERIMENT 5}

It is known that detection precedes identification or classification for many stimuli (Breitmeyer, 1984; Dick \& Dick, 1969; Smythe \& Finkel, 1974). This experiment was designed to compare the detection threshold to the classification threshold. By so doing, we hoped to get a precise estimate of the interval separating the detection from the classification threshold for both normal and rearranged faces.

Two conditions of face type (normal vs. rearranged) and two conditions of task (detect vs. classify) were crossed in a within-subjects design. A two-alternative temporal forced-choice detection task was used. Under the conditions of the detection task, the subject simply indicated the temporal interval that contained the face. In the classification task, the subject had to name the face type as well as indicate which temporal interval it occupied.

\section{Method}

Subjects. Twenty-two naive subjects from introductory psychology classes participated in this experiment.

Apparatus. A Gerbrands four-channel tachistoscope was used to present stimuli. The normal and rearranged faces used in this experiment were similar to those used in Experiment 4. These faces were $1.31^{\circ}$ wide and $1.09^{\circ}$ high. Unlike Experiment 4 , these faces were presented at the point of fixation. The fixation field contained a cross hair with its center removed thus creating a $2.75^{\circ}$ high $\times$ $3.63^{\circ}$ wide clear area within which to present the face. The face stimulus (normal or rearranged) was presented in the center of this area. This arrangement afforded the subjects a well-delineated fixation area that did not overlap with the contours of the target. The fixation, target, and mask fields were $9^{\circ}$ wide $\times 6^{\circ}$ high. The fixation and mask fields were set at $20.56 \mathrm{~cd} / \mathrm{m}^{2}$; the target field was set at $27.41 \mathrm{~cd} / \mathrm{m}^{2}$. The duration of the face field was set at $20 \mathrm{msec}$, and the mask duration was set at $100 \mathrm{msec}$. The mask was made up of letters and broken pieces of letters. It formed a disk with a diameter of $5^{\circ}$. The fixation field terminated with the onset of the mask and returned $2 \mathrm{sec}$ after the mask offset.

Procedure. The procedures of Experiment 5 differed in terms of the instructions given. In the detection condition, subjects were told that their task would be to tell in which of two presentation intervals the stimulus had been presented. They were told that they were to report the interval that contained any hint of a stimulus, whether or not they could tell if the stimulus was a normal or rearranged face. They were told that, at times, they might feel as though they had seen nothing but the mask during both presentations. They were further told that regardless of whether or not they thought they saw a stimulus, they were to make a choice, even if they had to guess as to which temporal interval contained the face stimulus. The subjects were not allowed to omit a response.

In the classification condition, subjects were given slightly different instructions. They were instructed to make two responses on each trial. The first response was to indicate their choice of face type for that trial, and the second, to indicate in which temporal interval they saw their choice. For example, a subject would respond "normal-one" if they wished to report a normal face in the first temporal interval. In the classification condition, a response was not scored as correct unless the subject got both face type and temporal interval correct. This was done to minimize the potential effects of response bias with regard to face type. Two additional features of the classification procedure also guarded against response-bias effects. The subjects were told explicitly that one half of the trials would contain a normal face and that the other half would contain a rearranged face. In addition, the PEST procedure itself provides, on average, that both stimulus types be presented at equal intervals above the threshold an equal number of times. Thus, the subjects would have the experience of seeing both face types equally well on an equal number of trials, provided that normal faces and rearranged faces gave the same psychometric function. As in the detection condition, the subjects were instructed to make both responses even if they had to guess.

Each trial consisted of two presentations. Before Presentation 1, the experimenter told the subject the type of trial (detection or classification). The experimenter then signaled the beginning of each trial by saying "ready one." This was followed by the first presentation sequence of the target field, ISI, mask, and blank white field. For Presentation 2, the experimenter said "two," and the second presentation sequence followed. The fixation field terminated with the offset of the target field, and the ISI was dark. Each presentation was separated by approximately $3 \mathrm{sec}$. For two of these seconds, the viewing field was homogeneous white. This homogeneous field was replaced by the fixation field during the approximately $1 \mathrm{sec}$ just prior to Presentation 2. The subjects were told that when the fixation field appeared, they were to fixate and await the cue for the next trial. The intertrial interval was about $7 \mathrm{sec}$. The subjects were told that their best performance would be obtained if they were careful to look at the fixation area during the trial.

The subjects' task was to make the response appropriate to the condition on that trial. If they were in the detection condition, they were to respond "one" or "two," depending on which interval they judged to contain the face. If they were in the classification 
condition, they made a choice of face type before they indicated the presentation interval containing the face. The subjects were instructed to respond only after seeing both presentations.

Each subject was practiced and run on two types of trials. The order of the two trial types was random, with pretrial verbal cuing by the experimenter as to the trial type (detection or classification). Both face types were run equally often under both task types. Both the temporal interval of the face and the type of face presented were randomly counterbalanced, with the constraint that both be presented an equal number of times. Forty trials were used to determine the Best PEST 75\% correct threshold SOA for the two tasks and face types. Accordingly, each subject received a total of 160 experimental trials, in random order, during the course of the experiment.

\section{Results and Discussion}

Of the 22 subjects run in this experiment, the data from 7 were not included in the primary data analysis because their classification threshold SOA for the rearranged face was $115 \mathrm{msec}$. Since this was the maximum SOA permitted by the implementation of PEST used in this experiment, we could not be sure of the true threshold values for these subjects. Because the decision to remove the data of these 7 subjects was done post hoc, we will include ANOVAs with and without their data. The repeated measures ANOVA on the data for all 22 subjects found the effects of task, face type, and their interaction to be significant at $p<.001$, yielding, respectively, $F(1,21)$ ratios of $78.80,38.30$, and 27.24.

As can be seen in Table 1, the detection threshold SOA is higher for the rearranged face than for the normal face and the classification threshold is disproportionately higher for the rearranged face than for the normal face. Essentially the same pattern of result is found for the 15 subjects for whom we are confident that valid thresholds were determined. The effects of face type $[F(1,14)=15.27$, $p<.005]$ and task $[F(1,14)=39.95, p<.001]$, and their interaction $[F(1,14)=8.74, p<.025]$, were statistically significant. The greatest change due to the removal of the data for the 7 subjects can be seen in the rearranged classification condition. The average threshold drops as the invalid data is removed. It is important to note that the classification threshold for normal faces was not increased with the removal of the invalid data from the 7 excluded subjects.

Planned comparisons found that the normal face differed from the rearranged face under detection $[F(1,14)=$ $6.975, p<.025]$ and under classification $[F(1,14)=$ $13.19, p<.005]$. The threshold for the detection of a normal face was also significantly lower than the threshold for classification of a normal face $[F(1,14)=16.53, p<$ $.005]$.

Table 1

Mean Threshold SOAs (msec) for the Normal and Rearranged Faces under the Detection and Classification Conditions of Experiment 5

\begin{tabular}{|c|c|c|c|c|}
\hline \multirow[b]{3}{*}{ Task } & \multicolumn{4}{|c|}{ Face Type } \\
\hline & \multicolumn{2}{|c|}{ Normal } & \multicolumn{2}{|c|}{ Rearranged } \\
\hline & 15 Subjects & All 22 Subjects & 15 Subjects & All 22 Subjects \\
\hline Detect & 29.87 & 30.14 & 36.60 & 37.82 \\
\hline Classify & 40.40 & 39.36 & 68.73 & 83.59 \\
\hline
\end{tabular}

Just considering the data on the 15 selected subjects, the differences between normal and rearranged faces for the detection and classification tasks were 6.73 and $28.33 \mathrm{msec}$, respectively. These results are consistent with the results of the previous experiments, which demonstrated lower detection thresholds for normal than for inverted faces. In addition, the initial detection advantage for normal faces is amplified when the task requires classifying the type of face.

The hypothesis that observers were responding to a simple change in the visual field, at the detection threshold, was supported by the demonstration in Experiment 5 that target detection takes place at shorter SOAs than does target classification. Furthermore, this suggests that different face types, although not directly identifiable as such, are able to produce differential effects on perceptually driven behavior.

\section{EXPERIMENT 6}

Experiment 6 was designed to determine whether or not the FDE would generalize across different facial stimuli within the same experiment. In our previous experiments, we tested the generality of the FDE by using different faces across experiments. Experiment 6 was motivated by the concerns of an anonymous reviewer that the FDE might be the result of an observer's picking out some critical feature or features from the normal face while not being able to pick out a particular feature when presented as part of a rearranged or an inverted face. As an objection to the occurrence of a configuration-dependent detection effect, this begs the question. The objection simply restates that the detection of a single item might be affected by the features that surround the item. But our subjects were told simply to detect the location of the stimulus, not a particular stimulus item. Why is it, then, that the observer cannot use one of the surrounding features to detect the presence of the entire stimulus? Regardless of how one might try to answer this question, it seems to us that one has to hypothesize that it is the specific arrangement of the stimulus features which facilitates the detection of the stimulus-and that is what we mean by the face-detection effect.

The idea that the FDE might be restricted to a single face with which the observer becomes especially familiar as he or she participated in the experiment does suggest an interesting means of further documenting the FDE, however. And it is true that the strategy of searching for a particular feature rather than any feature of a particular type or form might affect the detection SOA of a subject. To minimize the contribution of such a strategy to the FDE, we conducted the following experiment, using three faces and their counterparts, which consisted of rearranged features of the stimulus faces.

\section{Method}

Subjects. Twenty-four volunteers from the introductory psychology classes at Oakland University served as subjects. The data from 2 of these subjects were not used because the subjects could not 
see the targets at the maximum SOA of $95 \mathrm{msec}$ provided by the software and hardware of our apparatus.

Apparatus. The apparatus was the same as in Experiment 4, with the exception that the fixation field remained on throughout the experiment. The luminance of this fixation field was $27.41 \mathrm{~cd} / \mathrm{m}^{2}$. Figure 2 contains the normal and rearranged versions of the stimuli used in this experiment. These stimuli were created with an Apple Macintosh computer running the Mac-a-Mug face-construction program. They were printed on an Apple Image Writer. These stimuli subtended $1.38^{\circ}$ horizontally and $1.25^{\circ}$ vertically. As required, they were centered on locations $2.09^{\circ}$ right or left of the fixation point.

Procedure. The procedure was the same as in Experiment 4, with the exception that thresholds were determined for normal and rearranged versions of three faces. The threshold for each of these six conditions was determined with the Best PEST algorithm over the course of 34 trials per condition. Feedback was given after every trial. A total of 204 experimental trials were run for each subject.

Each subject experienced the six conditions of face stimuli in a randomized order. This random sequence was constrained by the fact that each stimulus was tested an equal number of times. The position of the stimulus, left or right of the fixation point, was determined randomly, with the constraint that each stimulus appear to the right and left positions an equal number of times.

\section{Results and Discussion}

Normal faces gave shorter SOA thresholds than did rearranged faces. Normal and rearranged faces gave thresholds of 53.32 and $66.41 \mathrm{msec}$ for Face 1, 50.73 and $59.73 \mathrm{msec}$ for Face 2, and 52.50 and $62.23 \mathrm{msec}$ for Face 3. A repeated measures ANOVA gave significant effects of face type $[F(1,21)=20.96, p<.001]$ and face $[F(2,42)=3.50, p<.04]$. The interaction of face type $X$ face was not significant $[F=0.65]$. These results demonstrate, at least to a limited extent, that the FDE generalizes to different faces not only between experiments, but within a single experiment as well.

\section{EXPERIMENT 7}

Experiment 7 was designed for two purposes. One was to assess the effects of practice and feedback on the magnitude of the FDE. The second was to investigate the effect of the point around which the face is rotated to the inverted position. To determine the joint effects of practice and feedback, we conducted the experiment in two trial blocks. In the first trial block, subjects were run for

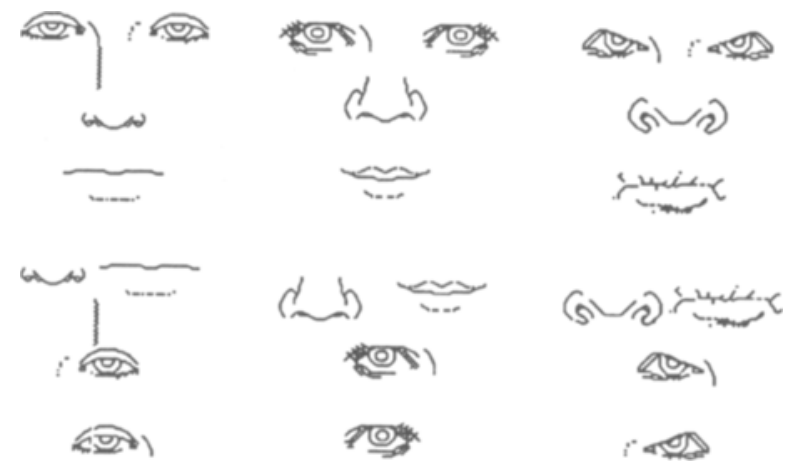

Figure 2. Face 1, Face 2, and Face 3, and their rearranged counterparts, are depicted from left to right (Experiment 6).
40 trials per condition with no feedback. In the second trial block, subjects were run, with feedback, for an additional 40 trials per condition. Two results might be expected from such an experiment. To the extent that practice and feedback are effective, we should find that thresholds for all conditions would be lower at the end of the trial block with feedback than they were at the end of the no-feedback trial block. Furthermore, if the FDE is somehow an effect based on the responses of naive subjects, we should find a smaller FDE for threshold-setting trial blocks in which feedback is given.

In the previous experiments that compared normal with inverted faces, the inverted face was created by rotating the face $180^{\circ}$ around its midpoint. This meant that the point of rotation was located in the nose region of the face. This procedure not only inverted the face, but also produced maximum changes in the locations of the eyes and mouth, while the location of the nose changed little. If one single feature is important to the detection of the face, then large changes in that feature's location might be responsible for the FDE when normal faces are compared with inverted faces. Indeed, Fraser and Parker (1986, p. 45) found that eyes are processed more efficiently than are other facial features.

This experiment tested two points of rotation. Faces were rotated either around the eyes or around the mouth. Rotation around the eyes would keep the location of the eyes constant between the two conditions of orientation while producing a large change in the location of the mouth. Just the opposite effect would be produced by rotation around the mouth. The independent variables of face orientation (normal vs. inverted), point of rotation (eye vs. mouth), and trial block were investigated in a completely crossed within-subjects design.

The order of testing of the variables of face orientation and point of rotation were randomly counterbalanced, with the constraint that each condition be presented an equal number of times within each trial block. In the first trial block (TB-1), no feedback was given as to the correctness of the subject's response. In the second trial block (TB-2), feedback was given. TB-2 further differed from TB-1 in that the practice that subjects had in TB-1 should have a positive carryover effect on TB-2. Feedback was thus confounded with practice. Such a confound would generally be of concern in determining the exact cause of a decrease in the magnitude of the FDE. However, in the present experiment, our objective was to see if the FDE could be eliminated by either practice or feedback. Secondly, we were interested to see if feedback and practice would attenuate the FDE differently as the point of the face's rotation was changed. The three independent variables of face orientation, point of rotation, and trial block were tested in a completely crossed within-subjects design.

\section{Method}

Subjects. The subjects were 14 naive volunteers from introductory psychology classes at Oakland University. Three of these subjects did not provide usable data; 2 of them could not see the tar- 
gets under the maximum SOA of $115 \mathrm{msec}$, and 1 could not be masked under any of the conditions of the experiment.

Apparatus. The apparatus was the same as that used in Experiments 3,4 , and 6 . The four face stimuli were photocopies of a female face trimmed so that just the eyes, nose, and mouth were visible. These stimuli were matched by eye for contrast and then assigned randomly to conditions. Two of the stimuli, one normal and the other inverted, were positioned so that the mouth would be on an imaginary horizontal line running through the point of fixation. This defined the mouth rotation condition. The other two stimuli, normal and inverted, were positioned so that the eyes were on this horizontal line. This defined the eye rotation condition. The face stimuli subtended a visual angle of approximately $1^{\circ}$ in height and $1.25^{\circ}$ in width. They could be positioned, as required by the forced-choice condition, so that they were centered $1.1^{\circ}$ right or left of the $0.13^{\circ}$ fixation point. The luminance of the target field was set at $48 \mathrm{~cd} / \mathrm{m}^{2}$; the luminance of the mask and fixation fields was set at $41 \mathrm{~cd} / \mathrm{m}^{2}$. However, the intensity of the target field was reduced by a 0.1 log unit filter. This was done to keep the obtained values of SOA above the $1-\mathrm{msec}$ floor permitted by the equipment and software. The fixation and mask fields were $8^{\circ}$ square, and the target field was $4.4^{\circ}$ square. The mask was the same as that used in Experiments 1, 2, 3, 4, and 6.

Procedure. Thresholds for each of the eight conditions of this experiment were based on $\mathbf{4 0}$ trials per condition. Accordingly, each subject received a total of 320 trials. These trials were run in two separate blocks (TB-1, TB-2) of 160 trials each. These two trial blocks were conducted about 1 week apart. Each subject was run under the no-feedback conditions of TB-1 before the feedback conditions of TB-2. The order of the four conditions within each trial block was counterbalanced randomly, with the stipulation that each condition be run an equal number of times.

\section{Results and Discussion}

As can be seen in Table 2, face orientation had a significant effect on the threshold SOA $[F(1,10)=34.96$, $p<.001]$. On average, normal faces produced a threshold SOA of $34.30 \mathrm{msec}$ and inverted faces, a threshold of $45.59 \mathrm{msec}$. The effect of trial block was also significant $[F(1,10)=5.13, p<.05]$, with lower thresholds found under the feedback conditions of TB-2 (42.52 vs. $37.37 \mathrm{msec})$. Trial block interacted with point of rotation $[F(1,10)=5.14, p<.05]$. This interaction reflects the smaller effect of trial block on stimuli rotated around the mouth relative to stimuli rotated around the eyes. It seems that performance improves more for rotations about the eyes than for rotations about the mouth as a function of trial block. The interaction of face type with point of rotation was not statistically significant $[F(1,10)=3.14]$. The critical face orientation $\times$ trial

Table 2

Mean Threshold SOAs (msec) for the Normal and Inverted Faces under the Two Conditions of Point of Rotation (Eye vs. Mouth) for Trial Block 1 (TB-1) and Trial Block 2 (TB-2) of Experiment 7

\begin{tabular}{cccc}
\hline Rotation Point & Face Type & TB1 & TB2 \\
\hline \multirow{6}{*}{ Eye } & Normal & 35.73 & 29.45 \\
& Inverted & 52.82 & 43.27 \\
Mouth & Normal & 38.45 & 33.55 \\
& Inverted & 43.09 & 43.18 \\
\hline
\end{tabular}

block interaction was not statistically significant $[F(1,10)$ $=.057]$. Nor was the three-way interaction of face orientation $\times$ trial block $\times$ point of rotation statistically significant $[F(1,10)=1.31]$.

There was no interaction between face orientation and trial block. Such an interaction would be expected if practice or feedback had reduced the magnitude of the FDE. However, this finding is not definitive. It is not clear what effects further trials with feedback might have had on the magnitude of the FDE. In general, the effects of trial block in Experiment 7 show that the practice and feedback manipulation was successful. Thus, it cannot be said that the failure to find a reduced FDE in TB-2 was due to a total failure of the practice and feedback manipulation. The finding that the FDE occurred without regard for the point of rotation suggests that it is not simply due to a displacement of a single critical feature away from the general area of fixation as the face is inverted.

\section{GENERAL DISCUSSION}

The cues used by our subjects to detect the presence of a facial stimulus have yet to be determined. Presenting subjects with only one type of facial stimulus (Experiment 3), either upright or inverted, removes the chance that the subject, in some sense, ignores visual cues if they are associated with a stimulus that does not match his or her perceptual set. The fact that the FDE can be obtained across subjects, with each group of subjects seeing only a single face type, makes it unlikely that the FDE is the result of a situation-specific perceptual set. The conscious operation, at the detection threshold, of a set of any kind is seriously challenged by the results of Experiment 5 . In essence, that experiment demonstrated that, at the detection threshold, subjects were not able to report the type of face presented.

It seems that people can detect facial stimuli at stimulus durations too short to allow the stimulus to be identified. By itself, this is not surprising. It is known that observers can localize a complex target without being able to identify it (Breitmeyer, 1974; Dick \& Dick, 1969; Smythe \& Finkel, 1974). What is counterintuitive about our results is that the processes underlying detection are influenced by the information contained in the arrangement of the pattern's individual components. It is as though the visual system, at some level, is able to determine where or when an interesting or familiar stimulus was presented. However, access to the information regarding the identity of that stimulus is not possible without further exposure to it.

We know of only one other task in which the informational qualities of a stimulus may have been shown to influence its perception before subjects were able to identify the stimulus. Avant and his co-workers (Avant \& Lyman, 1975; Avant, Lyman, \& Antes, 1975; Avant, Lyman, Skowronski, \& Millspaugh, 1977; Avant \& Thie- 
man, 1985) have shown that a subject's estimate of how long a stimulus was present is influenced by the meaningfulness of the stimulus.

There is much interest and controversy regarding the effect of visually masked stimuli on subsequent decision tasks. Some theorists have argued that a stimulus, masked below the level of identification, can still provide information about its semantic characteristics (e.g., Balota, 1983; Fowler, Wolford, Slade, \& Tassinary, 1981; Marcel, 1983a, 1983b; McCauley, Parmelee, Sperber, \& Carr, 1980). However, the evidence for unconscious processing of semantic meaning is unclear (Cheesman \& Merikle, 1984, 1985; Holender, 1986; Merikle, 1982; Nolan \& Caramazza, 1982; Purcell, Stewart, \& Stanovich, 1983). The present findings, and possibly those of Avant and his co-workers, suggest that the informational qualities of a visually masked stimulus can affect the perception of that stimulus. It is important to note, however, that neither the present experiments nor the experiments done in Avant's laboratory have revealed the nature of the information available to the observer or the degree to which this information can affect other judgments.

Mermelstein, Banks, and Prinzmetal (1979) used the notion of semantic recoding to account for the FSE (Homa et al., 1976). Mermelstein et al. postulated that both upright and inverted faces are seen equally well, but that a semantic code is evoked only by the upright face. The semantic code is generated when the emerging features of the face form a match with an appropriate memorial representation. This recoding need not include specific facial features. A semantic code, such as labeling a face as pleasant or angry, or giving it an identity ("looks like my grandmother"), is seldom elicited by rearranged facial features. According to Mermelstein et al., the FSE results because semantic codes can be more easily generated for normal faces than for inverted or rearranged faces.

The results of our experiments cannot be explained by semantic recoding. Only in Experiments 1 and 2, and then only occasionally, were our subjects aware of the type of face. A striking feature of our experiments is that our subjects would have no need to rely on a semantically recoded stimulus in order to locate the position of the stimulus. Nonetheless, our results do suggest that normal faces have an early-detection advantage, which could form the basis for the superior feature-identification effects documented by Homa et al. (1976) and by van Santen and Jonides (1978). Consistent with this argument is the finding of Experiment 5 that the classification threshold is disproportionately lower for normal faces than for rearranged faces. These data reinforce the contention of those authors that normal faces are simply seen better than are rearranged faces when they are presented for very brief durations, albeit durations above the subject's detection threshold (also see Purcell, Stewart, Botwin, \& Kreigh, 1983).
Rhodes (1985) has proposed a model that conceptualizes face recognition as taking place in distinct stages. The model is hierarchical and interactive, combining both bottom-up and top-down processing. Although it deals primarily with face recognition, our data suggest that processing of a face happens earlier than his model predicts, and therefore, like Mermelstein et al.'s (1979) model, Rhodes's model is not complete.

It is likely that the FDE is related to the FSE. The FDE is a manifestation of an earlier stage of visual processing, a stage that supports the FSE. The model proposed for the FSE by Homa et al. (1976) suggests that the advantage of normal over rearranged faces is of a perceptual nature, so that normal faces are seen more clearly than are rearranged faces at comparable SOA values. A mechanism for this was suggested by van Santen and Jonides (1978), who proposed that the stimulus was recoded into a more abstract visual form. Once recoded, the facial stimulus would become less susceptible to the noncoded input of a masking stimulus. Van Santen and Jonides further hypothesized that coding would be more efficient for normal than for rearranged faces. While it is not clear what the nature of this recoding might be, van Santen and Jonides suggested that individual features might be mapped into a unitary facial representation. Recent neurophysiological work lends plausibility to such an idea.

The visual system of monkeys seems to contain facespecific perceptual units (Bruce, Desimone, \& Gross, 1981; Perrett, Rolls, \& Caan, 1982; Perrett et al., 1984; Perrett et al., 1985; Rolls, 1984; Rolls, Baylis, \& Leonard, 1985). These face-specific units half response latencies as brief as $80 \mathrm{msec}$ (Perrett et al., 1982) and the following properties: They respond weakly, if at all, to rearranged faces or to other visual stimuli. Of the units that respond to upright faces, only about half respond to inverted faces. Latencies increase by 10 to $60 \mathrm{msec}$ as the face is rotated from the upright. Analogous units in human beings might serve as the biological mechanism underlying the FDE. Although such an approach is attractive, more work needs to be done to correlate the neurophysiology of these face-specific units with the psychophysical conditions that produce the FDE. Regardless of the underlying neurophysiological mechanisms, the existence of an FDE indicates that the informational properties of a stimulus can affect its detectability.

The FDE seems to be neither wholly perceptual nor wholly cognitive. Its rather delicate position between perception and cognition is seen most easily when the FDE is compared with Fodor's definition of a perceptual module. The FDE appears to represent a process that "is smart like cognition in that it is typically inferential" (Fodor, 1985, p. 2); why else would the detectability of a face depend upon the arrangement of facial features rather than on the features themselves? Yet the FDE is "dumb like reflexes in that it is typically encapsulated [so that feedback does not eliminate it. The FDE seems to be the result 
of] an inference-making mechanism whose access to background information is constrained by general features of cognitive architecture, hence relatively rigidly and relatively permanently constrained"' (Fodor, 1985, p. 3). And it is an architecture "built to detect what is right here, right now" (Fodor, 1985, p. 4), in the strongest sense of the word detect.

\section{REFERENCES}

Avant, L. L., \& Lyman, P. J. (1975). Stimulus familiarity modifies perceived duration in prerecognition visual processing. Journal of Experimental Psychology: Human Perception \& Performance, 1, 205-213.

Avant, L. L., Lyman, P. J., \& ANTES, J. R. (1975). Effects of stimulus familiarity upon judged visual duration. Perception \& Psychophysics, 17, 253-262.

Avant, L. L., Lyman, P. J., Skowronsk, M., Millspaugh, J. R. (1977). Perceived tachistoscopic duration and early visual processing in preschool children and adults. Journal of Experimental Child Psychology, 23, 348-366.

Avant, L. L., \& Thieman, A. A. (1985). On visual access to letter case and lexical/semantic information. Memory \& Cognition, 13, 392-404.

BALOTA, D. (1983). Automatic semantic activation and episodic memory encoding. Joumal of Verbal Learning \& Verbal Behavior, 22, 88-104.

Biederman, I. (1972). Perceiving real world scenes. Science, 177, $77-80$.

BREITMEYER, B. G. (1984). Visual masking: An integrative approach. New York: Oxford University Press

Bruce, C., Desimone, R., \& Gross, C. G. (1981). Visual properties of neurons in a polysensory area in superior temporal sulcus of the macaque. Journal of Neurophysiology, 46, 369-384.

Cheesman, J., \& Merikle, P. M. (1984). Priming with and without awareness. Perception \& Psychophysics, 36, 387-395.

Chemsman, J., \&e Merikle, P. M. (1985). Word recognition and consciousness. In D. Besner, T. G. Waller, \& G. E. MacKinnon (Eds.), Reading research: Advances in theory and practice (Vol. 5, pp. 331353). New York: Academic Press.

Dember, W. N., \& WARM, J. S. (1979). Psychology of perception. New York: Holt, Rinehart \& Winston.

Dick, A. O., \& Dick, S. O. (1969). An analysis of hierarchical processing in visual perception. Canadian Joumal of Psychology, 23, 203-211.

EnNS, J. T., \& Prinzmetal, W. (1984). The role of redundancy in the object-line effect. Perception \& Psychophysics, 35, 22-32.

FoDor, J. A. (1985). Precis of the modularity of mind. Behavioral \& Brain Sciences, 8, 1-42.

Fowler, C. A., Wolford, G., Sllade, R., \& Tassinary, L. (1981). Lexical access with and without awareness. Journal of Experimental Psychology: General, 110, 341-362.

Fraser, I. H., \& Parker, D. M. (1986). Reaction time measures of feature saliency in a perceptual integration task. In H. D. Ellis, M. A. Jeeves, F. Newcombe, \& A. Young (Eds.), Aspects of face processing (pp. 45-52). Dordrecht: Martinus Nijhoff.

Gyoba, J., Arimura, M., \& Maruyama, K. (1980). Visual identification of line segments embedded in human face patterns. Tohoku Psychologica Folia, 39, 113-120.

HOLENDER, D. (1986). Semantic activation without conscious identification in dichotic listening, parafoveal vision, and visual masking: A survey and appraisal. Behavioral \& Brain Sciences, 9, 1-66.

Homa, D., Haver, B, \& Schwartz, T. (1976). Perceptibility of schematic face stimuli: Evidence for a perceptual Gestalt. Memory \& Cognition, 4, 176-185.

JohnSton, J. C. , \& MCCLELland, J. L. (1973). Visual factors in word perception. Perception \& Psychophysics, 14, 365-370.

KAHNEMAN, D. (1968). Methods, findings and theory in studies of visual masking. Psychological Bulletin, 70, 404-425.
Lanze, M., Maguire, W., \& Weisstein, N. (1985). Emergent features: A new factor in the object-superiority effect? Perception \& Psychophysics, 38, 438-442.

Lieberman, H. R., \& Pentland, A. P. (1982). Microcomputer-based estimate of psychophysical thresholds: The Best PEST. Behavior Research Methods \& Instrumentation, 14, 21-25.

MARCEL, A. J. (1983a). Conscious and unconscious perception: Experiments on visual masking and word recognition. Cognitive Psychology, 15, 197-237.

MARCEL, A. J. (1983b). Conscious and unconscious perception: An approach to the relations between phenomenal experience and perceptual processes. Cognitive Psychology, 15, 238-300.

McCauley, C., Parmelee, C. M., Sperber, R. D., \& Carr, T. H. (1980). Early extraction of meaning from pictures and its relation to conscious identification. Journal of Experimental Psychology: Human Perception \& Performance, 6, 265-276.

Merikle, P. M. (1982). Unconscious perception revisited. Perception \& Psychophysics, 31, 298-301

Mermelstein, R., Banks, W., \& Prinzmetal, W. (1979). Figural goodness effects in perception and memory. Perception \& Psychophysics, 26, 472-480.

Nolan, K. A., \& Caramazza, A. (1982). Unconscious perception of meaning: A failure to replicate. Bulletin of the Psychonomic Society, 20, 23-26.

Perrett, D. I., Rolls, E. T., \& CAAN, W. (1982). Visual neurones responsive to faces in the monkey temporal cortex. Experimental Brain Research, 47, 329-342.

Perrett, D. I., Smith, P. A. J., Potrer, D. D., Mistlun, A. J., Head, A. S., Milner, A. D., \& JeEves, M. A. (1984). Neurones responsive to faces in the temporal cortex: Studies of functional organization, sensitivity to identity, and relation to perception. Human Neurobiology, 3, 197-208.

Perrett, D. I., Smith, P. A. J., Potrer, D. D., Mistlun, A. J., Head, A. S., Milner, A. D., JeEves, M. A. (1985). Visual cells in the temporal cortex sensitive to face view and gaze direction. Proceedings of the Royal Society (London), B223, 293-317.

Purcell, D. G., \& StewArT, A. L. (1981). A face superiority effect. Bulletin of the Psychonomic Society, 18, 312. (Abstract)

Purcell, D. G., \& Stewart, A. L. (1985). The face detection effect. Bulletin of the Psychonomic Society, 23, 288. (Abstract)

Purcell, D. G., \& Stewart, A. L. (1986). The face detection effect. Bulletin of the Psychonomic Society, 24, 118-120.

Purcell, D. G., Stewart, A. L., Botwin, M., \& Kreigh, R. (1983). A face superiority effect: Hemiretina effects. Bulletin of the Psychonomic Society, 21, 185. (Abstract)

Purcell, D. G., Stewart, A. L., \& Stanovich, K. E. (1983). Another look at semantic priming without awareness. Perception \& Psychophysics, 34, 65-71.

Reicher, G. M. (1969). Perceptual recognition as a function of meaningfulness of stimulus materials. Journal of Experimental Psychology, 81, 275-280.

RHODES, G. (1985). Lateralized processes in face recognition. British Journal of Psychology, 76, 249-271.

Rolss, E. T. (1984). Neurons in the cortex of the temporal lobe and in the amygdala of the monkey with responses selective for faces. Human Neurobiology, 3, 209-222.

Rolls, E. T., Baylis, G. C., \& Leonard, C. M. (1985). Role of low and high spatial frequencies in the face-selective responses of neurons in the cortex in the superior temporal sulcus in the monkey. $\mathrm{Vi}$ sion Research, 25, 1021-1035.

ScHIF, W. (1980). Perception: An applied approach. Boston: Houghton Mifflin.

SERGENT, J. (1983). Role of the input in visual hemispheric asymmetries. Psychological Bulletin, 93, 481-512.

SmYTHE, L., \& Finkel, D. L. (1974). Masking of spatial and identity information from geometric forms by a visual noise field. Canadian Journal of Psychology, 28, 399-408.

SPOEHR, K. T., \& LEHMKUhLE, S. W. (1982). Visual information processing. San Francisco: W. H. Freeman. 
Van Santen, J. P. H., \& Jonides, J. (1978). A replication of the facesuperiority effect. Bulletin of the Psychonomic Society, 12, 378-380.

WEISSTEIN, N., \& HARRIS, C. S. (1974). Visual detection of line segments: An object-superiority effect. Science, 186, 752-755.

WheEler, D. D. (1970). Processes in word recognition, Cognitive Psychology, 1, 59-85.

Williams, M. C., \& Weisstein, N. (1984). The effect of perceived depth and connectedness on metacontrast functions. Vision Research, 24, 1279-1288.

\section{NOTES}

1. The stimulus was a picture of a Happy Face taken from p. 373 of Dember and Warm (1979).

2. The stimulus was a picture of a happy, female face taken from p. 378 of Schiff (1980).

(Manuscript received November 7, 1986; revision accepted for publication September 25, 1987.) 